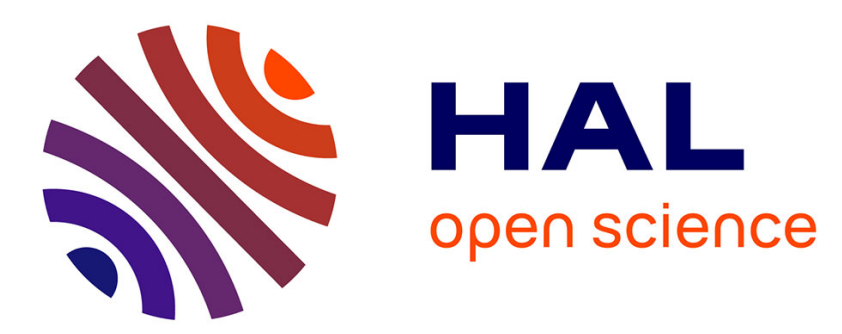

\title{
Nonlinear damping and forced vibration analysis of laminated composite beams
}

Hadj Youzera, Sid Ahmed Meftah, Noël Challamel, Abdelouahed Tounsi

\section{To cite this version:}

Hadj Youzera, Sid Ahmed Meftah, Noël Challamel, Abdelouahed Tounsi. Nonlinear damping and forced vibration analysis of laminated composite beams. Composites Part B: Engineering, 2012, 43 (3), pp.1147-1154. 10.1016/j.compositesb.2012.01.008 . hal-00768347

\section{HAL Id: hal-00768347 https://hal.science/hal-00768347}

Submitted on 7 Sep 2018

HAL is a multi-disciplinary open access archive for the deposit and dissemination of scientific research documents, whether they are published or not. The documents may come from teaching and research institutions in France or abroad, or from public or private research centers.
L'archive ouverte pluridisciplinaire HAL, est destinée au dépôt et à la diffusion de documents scientifiques de niveau recherche, publiés ou non, émanant des établissements d'enseignement et de recherche français ou étrangers, des laboratoires publics ou privés. 


\title{
Nonlinear damping and forced vibration analysis of laminated composite beams
}

\author{
Hadj Youzera ${ }^{a}$, Sid Ahmed Meftah ${ }^{\mathrm{a}, *}$, Noël Challamel ${ }^{\mathrm{b}}$, Abdelouahed Tounsi ${ }^{\mathrm{a}}$ \\ a Laboratoire des Matériaux et Hydrologie, Université de Sidi Bel Abbes, BP 89 Cité Ben M'hidi, 22000 Sidi Bel Abbes, Algeria \\ ${ }^{\mathrm{b}}$ Université Européenne de Bretagne, Université de Bretagne Sud, LIMATB Centre de Recherche, Rue de Saint Maudé, BP 92116,56321 Lorient cedex, France
}

\begin{abstract}
The purpose of the present work it to study the damping and forced vibrations of three-layered, symmetric laminated composite beams. In the analytical formulation, both normal and shear deformations are considered in the core by using the higher-order zig-zag theories. The harmonic balance method is coupled with a one mode Galerkin procedure for a simply supported beam. The geometrically nonlinear coupling leads to a nonlinear frequency amplitude equation governed by several complex coefficients. In the first part of the paper, linear and nonlinear damping parameters of laminated composite beams are obtained. In the second part, nonlinear forced vibration analysis is carried out for small and large vibration amplitudes. The frequency response curves are presented and discussed for various geometric and material properties.
\end{abstract}

\section{Introduction}

Fibre reinforced composites are widely used in the aerospace, automotive, nuclear, marine, biomedical and civil engineering. Composite materials can be tailored to offer a unique combination of material capabilities, which may include low density, high strength, high stiffness, high damping, chemical resistance, thermal shock resistance and others properties of interests. In order to control the resonant amplitudes of vibration and thus in extending service life of laminated composite beams under periodic load or impact, the damping in the core layer play an important role. At the constituent level, the energy dissipation in fibre-reinforced composites is induced by different processes such as the viscoelastic behaviour of the matrix, the damping at the fibre-matrix interface, the damping due to damage, etc. At the laminate level, damping is depending on the constituent layer properties as well as the layer orientations, interlaminar effects, stacking sequence, etc.

Most of the studies of laminated composite beams are devoted to linear vibration and damping analysis. Earlier works on this subject are done by Gibson and Plunkett [1] and Gibson and Wilson [2]. A good overview on the available literature dealing with the vibration behaviour in presence of viscoelastic material can be found in the survey articles by Nakra [3,4]. In the earlier works, some of the important contributions are the works of Heng et al. [5], He and Rao [6], Rikards [7] and Bhimaraddi [8]. In all these works, a complex modulus, which consists of a real part representing elastic stiffness

\footnotetext{
* Corresponding author.

E-mail addresses: meftahs@yahoo.com (S.A. Meftah), noel.challamel@univ-ubs.fr (N. Challamel).
}

and an imaginary part representing dissipation, has been widely used to model the behaviour of linear viscoelastic materials under harmonic vibrations. With respect to the introduction of geometrical nonlinearity for beams with viscoelastic cores, Kovac et al. [9] and Hyer et al. $[10,11]$ studied the nonlinear vibration of a damped sandwich beam. This study is based on a multi-mode Galerkin procedure coupled with the harmonic balance method.

Sandwich and laminated composite beams have been analysed using the classical models developed for one-layer beams (solid beams). These models are based on a theory that neglects transverse shear and normal strains and leads to the classical laminate theory (CLT) $[12,13]$. Due to the drawbacks of the CLT, a first order shear deformation theory (FSDT) has been proposed to take into account the transverse shear deformation [14-16]. The effects of the transverse shear deformation are pronounced for composite beams because of the high ratio of the extensional modulus to the transverse shearing modulus. The FSDT is widely used, and assumes a constant transverse shear strain in the thickness direction [17]. Therefore, a shear correction factor is generally used to adjust the transverse shear stiffness in dynamic analyses of laminates [18-21]. To avoid the use of a shear correction factor, higher order shear deformation theories (HSDTs) have been developed [22-24]. These theories are more realistic, since they give zero transverse shear stress condition at the top and bottom surface boundaries of the structure. The HSDTs have been successfully and extensively applied to design of multi-layered structural components. The discontinuity of some mechanical properties in the thickness direction represents a flaw in these theories. Also, it should be emphasised that recent research $[25,26]$ has shown that HSDTs considerably overestimate natural frequencies of 
soft-core sandwich plates. The HSDTs are therefore of limited values for analysing problems in which an accurate description of the transverse normal stress distribution and related consequences are of interest. To overcome such limitations, Kapuria et al. [27] have used zig-zag theories, satisfying the inter-laminar continuity of the transverse shear stresses, to predict the dynamic and buckling responses of laminated beams with arbitrary layouts.

The aim of this work is to develop a simple consistent theory for the nonlinear vibration analysis of laminated composite beams with large amplitudes. This theory couples the harmonic balance technique to Galerkin procedure. The nonlinear geometrical effect due to axial forces caused by axial restraints is modelled using higher order zig-zag theories, which incorporate various shear function models for the shear deformation in the core. The nonlinear amplitude-frequency and phase-frequency relationships are established. The nonlinear frequency value and, in turn, the system loss factor ratio are obtained for various amplitudes, for considering different geometric and material parameters.

\section{Viscoelastic model for composite materials}

The general form of linear theory of a viscoelastic body is given by [28]

$\sigma(t)=\int_{-\infty}^{t} Q_{i j k l}^{*}(t-\tau) d \varepsilon_{k l}(\tau)$

The moduli for a viscoelastic material are complex numbers. They have real and imaginary components and can be defined by

$Q_{i j k l}^{*}=Q_{i j k l}^{\prime}+i Q_{i j k l}^{\prime \prime}$

where $Q_{i j k l}^{*}$ are the complex moduli, $Q_{i j k l}^{\prime}$ are the storage moduli and $Q_{i j k l}^{\prime \prime}$ are the loss moduli. The assumption of a time independent Poisson's ratio has been used, by many authors [29,30], to simplify the characterisation of glass and carbon fibre-reinforced composite, under structural loading conditions. The Poisson's ratio is considered as real and constant.

For this case, the complex moduli can be written in matrix form as

$\left[Q^{*}\right]=\left[Q^{\prime}\right]+i\left[Q^{\prime \prime}\right][\eta]$

where $\eta$ are the loss factors.

If symmetry conditions of transversely isotropic materials are considered, only five storage modulus parameters and three damping coefficients are independent. The two matrices defined in Eq.

(3) can be expressed in matrix form as [31]

$$
\left[Q^{\prime}\right]=\left[\begin{array}{cccccc}
Q_{11}^{\prime} & Q_{12}^{\prime} & Q_{12}^{\prime} & 0 & 0 & 0 \\
Q_{12}^{\prime} & Q_{22}^{\prime} & Q_{23}^{\prime} & 0 & 0 & 0 \\
Q_{12}^{\prime} & Q_{23}^{\prime} & Q_{22}^{\prime} & 0 & 0 & 0 \\
0 & 0 & 0 & Q_{44}^{\prime} & 0 & 0 \\
0 & 0 & 0 & 0 & Q_{66}^{\prime} & 0 \\
0 & 0 & 0 & 0 & 0 & Q_{66}^{\prime}
\end{array}\right]
$$

and

$$
[\eta]=\left[\begin{array}{cccccc}
\eta_{1} & 0 & 0 & 0 & 0 & 0 \\
0 & \eta_{2} & 0 & 0 & 0 & 0 \\
0 & 0 & \eta_{2} & 0 & 0 & 0 \\
0 & 0 & 0 & \eta_{2} & 0 & 0 \\
0 & 0 & 0 & 0 & \eta_{6} & 0 \\
0 & 0 & 0 & 0 & 0 & \eta_{6}
\end{array}\right]
$$

Therefore, according to this mathematical model, the viscoelastic constitutive relationships of transversely isotropic materials can be described in term of eight parameters; five independent dynamic stiffness parameters, $E_{1}^{\prime}, E_{2}^{\prime}, G_{12}^{\prime}, v_{12}$ and $v_{23}$, plus three independent damping loss factors $(\tan \delta), \eta_{1}, \eta_{2}$ and $\eta_{6}$ written as follows:

$Q_{11}^{\prime}=\frac{E_{1}^{\prime}}{1-v_{12} v_{12}}$

$Q_{22}^{\prime}=\frac{E_{2}^{\prime}}{1-v_{12} v_{12}}$

$Q_{12}^{\prime}=\frac{E_{2}^{\prime}}{1-v_{12} v_{12}}$

$Q_{55}^{\prime}=Q_{66}^{\prime}=G_{13}^{\prime}=G_{12}^{\prime}$

$Q_{44}^{\prime}=\frac{E_{2}^{\prime}}{2+2 v_{12}}$

$v_{21}=\frac{v_{12} E_{2}^{\prime}}{E_{1}^{\prime}}$

The normal and tangential stress $\sigma_{2}$ and $\tau$, can be expressed as functions of strains by means of the stiffness matrix

$\left\{\begin{array}{l}\sigma_{2} \\ \tau_{2}\end{array}\right\}=\left[\begin{array}{cc}\bar{Q}_{11}^{*} & 0 \\ 0 & \bar{Q}_{55}^{*}\end{array}\right]\left\{\begin{array}{c}\varepsilon_{2} \\ \varepsilon_{13}\end{array}\right\}$

in which

$\bar{Q}_{11}^{*}=Q_{11}^{\prime}\left(1+i \eta_{1}\right) m^{4}+\left(Q_{12}^{\prime}\left(1+i \eta_{1}\right)+Q_{12}^{\prime}\left(1+\eta_{2}\right)\right.$

$$
\left.+2 Q_{66}^{\prime}\left(1+\eta_{6}\right)\right) m^{2} n^{2}+Q_{22}^{\prime}\left(1+\eta_{2}\right) n^{4}
$$

$\bar{Q}_{55}^{*}=Q_{44}^{\prime}\left(1+\eta_{2}\right) n^{2}+Q_{55}^{\prime}\left(1+\eta_{6}\right) m^{2}$

where

$m=\cos \theta$ and $n=\sin \theta$

In which $\theta$ is the angle between the global axis and the local axis of the fibre in the composite material layer.

\section{Formulation}

\subsection{Kinematics}

The beam defined with dimensions and coordinate systems, is defined in Fig. 1. The laminated composite beam is considered with the coordinates $x$ along the length, $y$ along the width and $z$ along

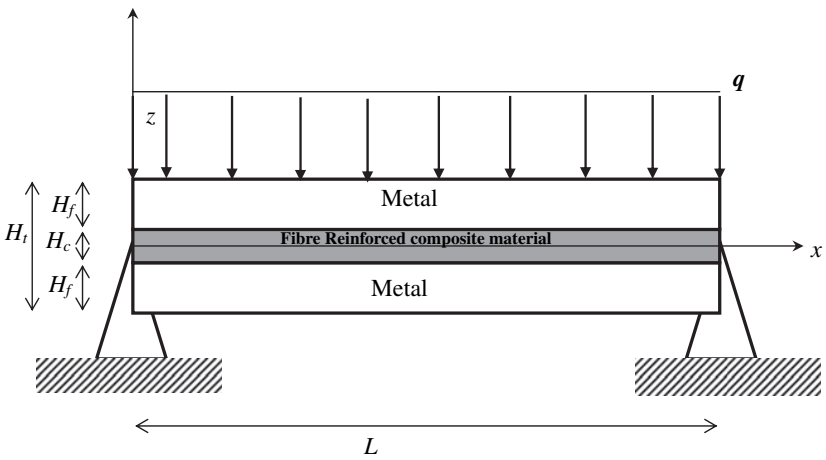

Fig. 1. Laminate beam with fibre Reinforced composite material core. 
Table 1

Kinematics models considered in the study.

\begin{tabular}{lll}
\hline Model & Name & $f(z)$ \\
\hline 1 & Timoshenko [17] & $f(z)=z$ \\
2 & Reddy [22] & $f(z)=z-4 z^{3} / 3 H_{c}^{2}$ \\
3 & Touratier [23] & $f(z)=H_{c} \sin \left(\pi z / H_{c}\right) / \pi$ \\
4 & Afaq [24] & $f(z)=z e^{-2\left(z / H_{c}\right)^{2}}$ \\
\hline
\end{tabular}

the thickness directions as shown in Fig. 1. The faces and core layer thickness are $H_{f}$ and $H_{c}$, respectively. $L$ is the length and $H_{t}$ the total thickness of the beam. The derivation of the general governing equations is based on the following assumptions:

- No slipping occurs at the interfaces between the three layers of the beam.

- The kinematics of the beam is defined by the transverse displacement $w(x, t)$ and the independent rotation $\beta(x, t)$.

For the comparison of the various shear functions $f(z)$, the present work is limited to laminated composite and sandwich beams. In the higher order zig-zag theories, the displacement field is divided into three parts in order to satisfy displacement and transverse shear stresses continuity conditions at interfaces by introduction a shear function $f(z)$. The major drawback of these theories lies in the fact that the total number of the unknowns is dependent on the number of layers. The kinematics can be defined by

$$
\begin{aligned}
& u_{1}(x, z, t)=u_{1}^{0}(x, t)-\left(z-\frac{H_{c}+H_{f}}{2}\right) \frac{\partial w(x, t)}{\partial x} \quad \frac{H_{c}}{2}<z \leqslant \frac{H_{t}}{2} \\
& u_{2}(x, z, t)=u_{2}^{0}(x, t)-z \frac{\partial w(x, t)}{\partial x}+f(z) \beta(x, t), \quad-\frac{H_{c}}{2} \leqslant z \leqslant \frac{H_{c}}{2} \\
& u_{3}(x, z, t)=u_{3}^{0}(x, t)-\left(z+\frac{H_{c}+H_{f}}{2}\right) \frac{\partial w(x, t)}{\partial x} \quad-\frac{H_{t}}{2} \leqslant z \leqslant-\frac{H_{c}}{2}
\end{aligned}
$$

where $u_{i}(x, z, t)(i=1, \ldots, 3)$ is the longitudinal displacement along the thickness of the layer $i, u_{1}^{0}(x, t)(i=1, \ldots, 3)$ is the axial displacement of the layer mid-plane. $w(x, t)$ is the common transverse displacement and $\beta(x, t)$ is the additional rotation of the normal to the mid-plane. By choosing the appropriate mathematical form for the shear function in the core, new kinematics refinements for the core modelling can be represented in Table 1. Considering the continuity of the displacements at the interfaces, Eqs. (9)-(11) the displacement fields $u_{1}^{0}(x, t)$ and $u_{3}^{0}(x, t)$ can be expressed as function of $u_{2}^{0}(x, t)$ :

$$
\begin{aligned}
& u_{1}^{0}(x, t)=u_{2}^{0}(x, t)-\left(\frac{H_{c}+H_{f}}{2}\right) \frac{\partial w(x, t)}{\partial x}+f\left(\frac{H_{c}}{2}\right) \beta(x, t), \\
& u_{3}^{0}(x, t)=u_{2}^{0}(x, t)+\left(\frac{H_{c}+H_{f}}{2}\right) \frac{\partial w(x, t)}{\partial x}-f\left(\frac{H_{c}}{2}\right) \beta(x, t)
\end{aligned}
$$

Substituting Eqs. (12) and (13) into Eqs. (9) and (11), respectively, leads to the axial displacement fields written as:

$$
\begin{aligned}
& u_{1}=(x, z, t)=u_{2}^{0}(x, t)-z \frac{\partial w(x, t)}{\partial x}+f\left(\frac{H_{c}}{2}\right) \beta(x, t), \\
& u_{2}(x, z, t)=u_{2}^{0}(x, t)-z \frac{\partial w(x, t)}{\partial x}+f(z) \beta(x, t)
\end{aligned}
$$

$u_{3}(x, z, t)=u_{2}^{0}(x, t)-z \frac{\partial w(x, t)}{\partial x}-f\left(\frac{H_{c}}{2}\right) \beta(x, t)$

According to the assumption of small strains and moderate rotations, the nonlinear strain-displacement relations for each layer can be expressed in the following form [32,33]:

$\varepsilon_{1}(x, z, t)=\frac{\partial u_{1}(x, z, t)}{\partial x}+\frac{1}{2}\left(\frac{\partial w(x, t)}{\partial x}\right)^{2}$

$\varepsilon_{2}(x, z, t)=\frac{\partial u_{2}(x, t)}{\partial x}+\frac{1}{2}\left(\frac{\partial w(x, t)}{\partial x}\right)^{2}$

$\varepsilon_{3}(x, z, t)=\frac{\partial u_{3}(x, t)}{\partial x}+\frac{1}{2}\left(\frac{\partial w(x, t)}{\partial x}\right)^{2}$

$\gamma=\frac{\partial u_{2}(x, z, t)}{\partial z}+\frac{\partial w(x, t)}{\partial x}$

\subsection{Formulation of forced vibration problem}

The bending and membrane strains of the faces and the shear, bending and membrane strains of the composite interlayer are considered in the following formulation. In free vibration domain, the principal of virtual works is given by:

$\delta P_{\text {int }}=\delta P_{\text {ext }}-\delta P_{\text {acc }}$

$\delta P_{\text {ext }}$ is the virtual works done by external uniform distributed load $q(t)$ and $\delta P_{a c c}$ represents the resulting of virtual works put into the system as acceleration. The internal virtual work $\delta P_{\text {int }}$ is decomposed as

$\delta P_{\text {int }}=\delta P_{\text {int }}^{(1)}+\delta P_{\text {int }}^{(2)}+\delta P_{\text {int }}^{(3)}$

in which $\delta P_{\text {int }}^{(1)}+\delta P_{\text {int }}^{(2)}+\delta P_{\text {int }}^{(3)}$ are the virtual works of the upper metal, composite layer and lower metal respectively given by:

$$
\begin{aligned}
\delta P_{\text {lint }}^{(1)}= & \int_{0}^{L}\left[N_{1}\left(\frac{\partial u(x, t)}{\partial x}+\frac{\partial w(x, t)}{\partial x} \frac{\partial \delta w(x, t)}{\partial x}\right)-\left(\frac{H_{c}+H_{f}}{2}\right)\right. \\
& \left.N_{1} \frac{\partial^{2} \delta w(x, t)}{\partial x^{2}}+M_{1} \frac{\partial^{2} \delta w(x, t)}{\partial x^{2}}+\left(f\left(\frac{H_{c}}{2}\right) N_{1}\right)\left(\frac{\partial \delta \beta(x, t)}{\partial x}\right)\right] d x
\end{aligned}
$$

$$
\begin{aligned}
\delta P_{\text {lint }}^{(2)}= & \int_{0}^{L}\left\{N_{2}\left(\frac{\partial u(x, t)}{\partial x}+\frac{\partial w(x, t)}{\partial x} \frac{\partial \delta w(x, t)}{\partial x}\right)+\left(M_{2}\right) \frac{\partial^{2} \delta w(x, t)}{\partial x^{2}}\right) \\
- & Q_{11}^{*} b \int_{-H_{c} / 2}^{H_{c} / 2}\left[\left(f(z) z \frac{\partial^{2} w(x, t)}{\partial x^{2}}-f(z)^{2}\left(\frac{\partial \beta(x, t)}{\partial x}\right)\right] d z\right. \\
& \left.\frac{\partial \delta \beta(x, t)}{\partial x} d x+T \delta \beta(x, t)\right\} d x \\
\delta P_{\text {lint }}^{(3)}= & \int_{0}^{L}\left[N_{3}\left(\frac{\partial u(x, t)}{\partial x}+\frac{\partial w(x, t)}{\partial x} \frac{\partial \delta w(x, t)}{\partial x}\right)+\left(\frac{H_{c}+H_{f}}{2}\right)\right. \\
& \left.N_{3} \frac{\partial^{2} \delta w(x, t)}{\partial x^{2}}+M_{3} \frac{\partial^{2} \delta w(x, t)}{\partial x^{2}}-\left(f\left(\frac{H_{c}}{2}\right) N_{3}\right)\left(\frac{\partial \delta \beta(x, t)}{\partial x}\right)\right] d x
\end{aligned}
$$

Here, $N_{i}$ and $M_{i}(i=1, \ldots, 3)$ are the axial forces and the bending moments in the laminated composite beam. $T$ is the shear force in the core layer. They are defined by

$\left.N_{1}=E_{f} S_{f} \frac{\partial u_{1}}{\partial x}+\frac{1}{2}\left(\frac{\partial w}{\partial x}\right)^{2}\right)$ 
$M_{1}=E_{f} I_{f} \frac{\partial^{2} w}{\partial x^{2}}$

$\left.N_{3}=E_{f} S_{f} \frac{\partial u_{3}}{\partial x}+\frac{1}{2}\left(\frac{\partial w}{\partial x}\right)^{2}\right)$

$M_{3}=E_{f} I_{f} \frac{\partial^{2} w}{\partial x^{2}}$

$N_{2}=S_{c} \bar{Q}_{11}^{*}\left(\frac{\partial u_{2}(x, t)}{\partial x}+\frac{1}{2}\left(\frac{\partial w(x, t}{\partial x}\right)^{2}\right)$

$\left.M_{2}=I_{c} Q_{11}^{*} \frac{\partial^{2} w(x, t)}{\partial x^{2}}\right)-\int_{-H_{c} / 2}^{-H_{c} / 2} Q_{11}^{*} z f(z) \frac{\partial \beta(x, t)}{\partial x}$

$\left.T=b \int_{-H_{c} / 2}^{H_{c} / 2} \bar{Q}_{55}^{*}\left(\frac{\partial f(z)}{\partial z}\right)^{2} d z(\beta(x, t))\right)$

The geometrical quantities used in Eqs. (23a-g) are the cross sectional area $S_{f}$ and $S_{c}$ and the quadratic moments $I_{f}$ and $I_{c}$ of the faces and core layers. The virtual work expressions $\delta P_{e x t}$ and $\delta P_{a c c}$ are given respectively by:

$\delta P_{e x t}=\int_{0}^{L} q(t) \delta w(x, t) d x$

$\delta P_{a c c}=\left(2 \rho_{f} S_{f}+\rho S_{c}\right) \int_{0}^{L} \frac{\partial^{2} w(x, t)}{\partial t^{2}} \delta w(x, t) d x$

Using Eqs. (20)-(22), the variational relation Eq. (18) can be rewritten as:

$$
\begin{gathered}
\int_{0}^{L}\left[N_{T}\left(\frac{\partial u(x, t)}{\partial x}+\frac{\partial w(x, t)}{\partial x} \frac{\partial \delta w(x, t)}{\partial x}\right)+M_{\beta} \frac{\partial \delta \beta(x, t)}{\partial x}\right. \\
+M_{W} \frac{\partial^{2} \delta w(x, t)}{\partial x^{2}}+T(\delta \beta(x, t)] d x=\delta P_{e x t}-\delta P_{a c c}
\end{gathered}
$$

in which

$$
\begin{aligned}
& N_{T}(x, t)=\left(2 E_{f} S_{f}+S_{c} \bar{Q}_{11}^{*}\right) \varepsilon_{2}^{0} \\
& M_{w}=C_{1} \frac{\partial^{2} w(x, t)}{\partial x^{2}}-C_{2} \frac{\partial \beta(x, t)}{\partial x} \\
& M_{\beta}=-C_{2} \frac{\partial^{2} w(x, t)}{\partial x^{2}}+C_{3} \frac{\partial \beta(x, t)}{\partial x} \\
& T=C_{4} \beta(x, t)
\end{aligned}
$$

and

$$
\begin{aligned}
& C_{1}=2 E_{f} S_{f}\left(\frac{H_{c}+H_{f}}{2}\right)^{2}+2 E_{f} I_{f}+\bar{Q}_{11}^{*} I_{c} \\
& C_{2}=2 E_{f} S_{f}\left(\frac{H_{c}+H_{f}}{2}\right) f\left(\frac{H_{c}}{2}\right)+\bar{Q}_{11}^{*} b \int_{-H_{c} / 2}^{H_{c} / 2} z f(z) d z \\
& C_{3}=2 E_{f} S_{f} f\left(\frac{H_{c}}{2}\right)^{2}+\bar{Q}_{11}^{*} b \int_{-H_{c} / 2}^{H_{c} / 2} f(z)^{2} d z \\
& C_{4}=\bar{Q}_{55}^{*} b \int_{-H_{c} / 2}^{H_{c} / 2}\left(\frac{\partial f(z)}{\partial z}\right)^{2} d z
\end{aligned}
$$

\subsection{Nonlinear vibration mode and frequency-amplitude relationship}

For the study of nonlinear harmonic vibrations, the response is assumed to be harmonic and proportional to the linear vibration mode. Based on the one mode Galerkin approximation, the nonlinear response is sought by the following form of deflection and rotation functions:

$$
\begin{aligned}
& w(x, t)=\frac{\left(A e^{i \omega t}+\bar{A} e^{-i \omega t}\right)}{2} w(x) \\
& \beta(x, t)=\frac{\left(A e^{i \omega t}+\bar{A} e^{-i \omega t}\right)}{2} B(x)
\end{aligned}
$$

where $A$ is a complex unknown amplitude. The linear vibration mode of the undamped laminate beam, satisfies the following eigenvalue problem:

$$
\begin{aligned}
& \int_{0}^{L}\left[M_{\beta} \frac{\partial \delta B(x)}{\partial x}+M_{w} \frac{\partial^{2} w(x)}{\partial x^{2}}+T \delta B(x)\right] d x \\
& \quad=\left(2 \rho_{f} S_{f}+\rho_{c} S_{\theta}\right) \omega^{2} \int_{0}^{L} w \delta w(x) d x
\end{aligned}
$$

From this equation and by integrating by part, one finds the following differential equations:

$$
\begin{aligned}
& \frac{\partial M_{\beta}}{\partial x}-T=0 \\
& \frac{\partial^{2} M_{w}}{\partial x^{2}}=\left(2 \rho_{f} S_{f}+\rho_{c} S_{c}\right) \omega^{2} w(x)
\end{aligned}
$$

In the case of a simply supported beam, the boundary conditions are satisfied by the following expressions:

$$
\begin{gathered}
w(x)=\sin (k x) \\
B(x)=B \cos (k x)
\end{gathered} \quad \text { where } k=\frac{n \pi}{L}
$$

where the integer $n$ is the mode number. Inserting Eqs. (29), (30), and (35) into (34a), one gets the expression for $B$ as follows:

$B=\frac{C_{2} k^{3}}{C_{3} k^{2}+C_{4}}$

Applying the variational principle to the displacements $u, \beta$ and $w$, the following governing differential equations are obtained

$$
\begin{aligned}
& \frac{\partial N_{T}(x, t)}{\partial x}=0 \\
& \frac{\partial M_{\beta}}{\partial x}-T=0 \\
& -N_{T}(x, t) \frac{\partial^{2} w(x, t)}{\partial x^{2}}+\frac{\partial^{2} M_{w}}{\partial x^{2}}+\left(2 \rho_{f} S_{f}+\rho_{c} S_{c}\right) \frac{\partial^{2} w(x, t)}{\partial t^{2}}=q(t)
\end{aligned}
$$

Eq. (37a) leads to a constant axial force $N_{T}(x, t)=N(t)$. Assuming that the ends are immovable, from Eq. (37a), one gets the following expression of the axial force:

$N(t)=\frac{1}{L} \int_{0}^{L} N_{T}(x, t) d x=\frac{1}{2 L}\left(2 E_{f} S_{f}+\bar{Q}_{11}^{*} S_{c}\right) \int_{0}^{L}\left(\frac{\partial w(x, t)}{\partial x}\right)^{2} d x$

The substitution of Eqs. (28)-(30) into equations Eqs. (37b and 37c) and after some manipulation, one obtains a complex scalar differential equation similar to the ones established in [34-36] for linear calculation as given by

$$
\begin{aligned}
& D_{1} \frac{\partial^{6} w(x, t)}{\partial x^{6}}-D_{2} \frac{\partial^{4} w(x, t)}{\partial x^{4}}+D_{3} \frac{\partial^{2} w(x, t)}{\partial x^{2}}+D_{4} \frac{\partial^{4} w(x, t)}{\partial x^{2} \partial t^{2}} \\
& -D_{5} \frac{\partial^{2} w(x, t)}{\partial t^{2}}=-D_{6} q(t)
\end{aligned}
$$


where

$D_{1}=\frac{C_{1} C_{3}}{C_{2}}-C_{2}$

$D_{2}=\frac{C_{3}}{C_{2}} N(t)+\frac{C_{1} C_{4}}{C_{2}}$

$D_{3}=\frac{C_{4}}{C_{2}} N(t)$

$D_{4}=\frac{C_{3}}{C_{2}}\left(2 \rho_{f} S_{f}+\rho_{c} S_{c}\right)$

$D_{5}=\frac{C_{4}}{C_{2}}\left(2 \rho_{f} S_{f}+\rho_{c} S_{c}\right)$

$D_{6}=\frac{C_{4}}{C_{2}}$

In order to derive a simplified nonlinear amplitude-frequency equation, the expressions Eqs. (32) and (38) are inserted into Eq. (39). Using the harmonic balance method, a complex scalar nonlinear amplitude equation is then obtained as

$-\omega^{2} M A+K A+K_{n l} \bar{A} A^{2}=Q$

in which

$M=\frac{D_{5}}{D_{6}} \int_{0}^{L}(w(x))^{2} d x-\frac{D_{4}}{D_{6}} \int_{0}^{L} \frac{\partial^{2} w(x)}{\partial x^{2}} w(x) d x$

$K=\frac{C_{1} C_{4}}{D_{6} C_{2}} \int_{0}^{L} \frac{\partial^{4} w(x)}{\partial x^{4}} w(x) d x-\frac{D_{1}}{D_{6}} \int_{0}^{L} \frac{\partial^{6} w(x)}{\partial x^{6}} W(x) d x$

$K_{n l}=\frac{C_{3}}{D_{6} C_{2}} N(t) \int_{0}^{L} \frac{\partial^{4} w(x)}{\partial x^{4}} w(x) d x-\frac{D_{3}}{D_{6}} \int_{0}^{L} \frac{\partial^{2} w(x)}{\partial x^{2}} w(x) d x$

and

$Q=\int_{0}^{l} q(t) w(x) d x$

\subsection{Linear and nonlinear free vibration analysis}

The linear version of the amplitude Eq. (41) (with $Q=0$ ) leads to an approximate value of the complex eigenfrequency given by

$\omega^{2}=\frac{K}{M}=\Omega_{\text {lin }}^{2}\left(1+i \eta_{l}\right)$

where $\eta_{l}$ is the loss factor and $\Omega_{\text {lin }}$ is the linear frequency. Free vibration analysis of Eq. (41) (with $Q=0$ ) can be achieved by determining the relationship between the frequency $\omega^{2}$ and the amplitude $a=|A|$.

The nonlinear frequency and loss factor are defined as follows:

$\omega^{2}=\Omega_{n l}^{2}\left(1+i \eta_{n l}\right)$

\subsection{Solving the frequency-amplitude equation}

The nonlinear Eq. (41) can be rewritten in a simple form, and solved when $Q$ is not equal to zero. This $Q$ is assumed to be real number. The complex numbers $A, M, K$ and $K_{n l}$ can be rewritten as: $-\omega^{2} a|M| e^{i \xi}+|K| a e^{i \varphi}+a^{3}\left|K_{n l}\right| e^{i \psi}=Q e^{-i \chi}$

$A=a e^{i \chi}$

$: M=|M| e^{i \xi}$

$K=|K| e^{i \varphi}$

$K_{n l}=\left|K_{n l}\right| e^{i \psi}$

The corresponding real and imaginary terms of the above equations are given by:

$-\omega^{2} a|M| \cos (\xi)+a|K| \cos (\varphi)+a^{3}\left|K_{n l}\right| \cos (\psi)=Q \cos (\chi)$

$-\omega^{2} a|M| \sin (\xi)+a|K| \sin (\varphi)+a^{3}\left|K_{n l}\right| \sin (\psi)=-Q \sin (\chi)$

After some of manipulations, one obtains the following frequency-amplitude relation:

$\omega^{4}|M|^{2}-2 \alpha \omega^{2}+\lambda=0$

where

$\alpha=|M K| \cos (\xi-\varphi)+a^{2}\left|M K_{n l}\right| \cos (\xi-\psi)$

$\lambda=|K|^{2}+a^{4}\left|K_{n l}\right|^{2}+2 a^{2}\left|K K_{n l}\right| \cos (\varphi-\psi)-\frac{Q^{2}}{a^{2}}$

The solutions of Eq. (50) are as follows:

$\omega(a)=\frac{\sqrt{\alpha \pm \sqrt{\alpha^{2}-|M|^{2} \lambda}}}{|M|}$

where $\omega(a)$ is an amplitude dependent frequency for nonlinear forced vibration problem.

\section{Numerical results}

To objectively assess the various higher order zig-zag theories associated with the shear function $f(z)$ models listed in Table 1, linear and nonlinear free vibration analysis $(Q=0)$ are carried out. Laminated composite beams with simply supported edges are considered. The material and geometrical properties of the structure are given in Table 2. Results are obtained with MATLAB [37] developed for numerical application. The variation of the system loss factor ratio $\eta_{n l} / \eta_{l}$ of the laminated composite beams is studied. Fig. 2 presents on how the various shear function models influence the ratio $\eta_{n l} / \eta_{l}$. It can be found from these figures that the models of Reddy [22], Touratier [23] and Affaq [24] are accurate enough to predict satisfactory loss factor ratio $\eta_{n l} / \eta_{l}$. However, in the case of thin core with $H_{f} / H_{c}=7$, the Timoshenko model $(f(z)=z)$ underestimates the loss factor ratio $\left(\eta_{n l} / \eta_{l}\right)$, since this model cannot present exactly the transverse shear deformations. The influences of the fibre orientation on the loss factor ratio $\eta_{n l} / \eta_{l}$ are addressed in Fig. 3. The obtained results show no great dependence between $\eta_{n l} / \eta_{l}$ and the amplitude $(a / H)$ for stiff core with $\theta=0^{\circ}$.Unlike, in the case of soft core $\left(\theta=90^{\circ}\right)$, the dependence between $\eta_{n l} / \eta_{l}$ and

Table 2

Materiel and geometrical parameters.

\begin{tabular}{lll}
\hline Face layers & Composite core & Whole beam \\
\hline$E_{f}=2.1 .10^{11} \mathrm{~Pa}$ & $E_{1}=154.5 \mathrm{GPa}$ & $H=0.01 \mathrm{~m}$ \\
$\rho_{f}=7800 \mathrm{~kg} / \mathrm{m}^{3}$ & $E_{2}=9.9 \mathrm{GPa}$ & $b=4 \mathrm{H}$ \\
& $E_{3}=9.9 \mathrm{GPa}$ & \\
& $G_{12}=7.1 \mathrm{GPa}$ & \\
& $v_{23}=0.49$ & \\
& $v_{12}=0.35$ & \\
& $\eta_{1}=5.7 \times 10^{-3}$ & \\
& $\eta_{2}=8.5 \times 10^{-3}$ & \\
& $\eta_{6}=13.2 \times 10^{-3}$ & \\
$\rho_{c}=1566 \mathrm{~kg} / \mathrm{m}^{3}$ &
\end{tabular}



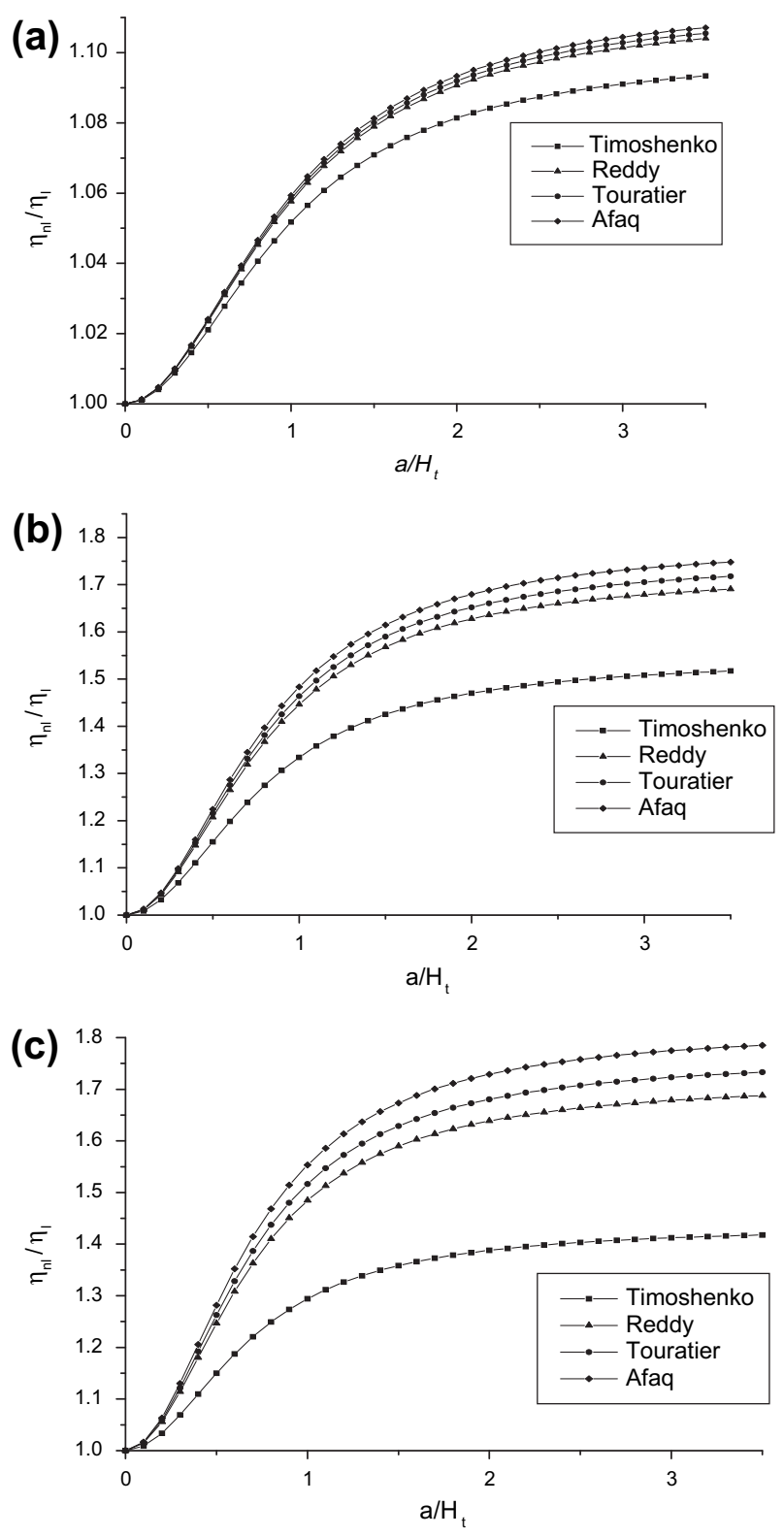

Fig. 2. Loss factor ratio $\eta_{n l} / \eta_{l}$ as a function of the amplitude $(a / H)$ for difference models with $\theta=90^{\circ}$ and $L / H=100$. (a) $H_{f} / H_{c}=1 / 7$; (b) $H_{f} / H_{c}=1$ and (c) $H_{f} / H_{c}=7$.

$(a / H)$ is more strong at small amplitudes $(a / H) \in[0 ; 2]$ and remain unchanged at large amplitudes.

The influences of the geometrical parameter $L / H$ on $\eta_{n l} / \eta_{l}$, are addressed in Fig. 4. From this figure, one can note that an important reduction of $\eta_{n l} / \eta_{l}$ is observed with respect to the amplitudes $(a / H)$ for short beams $(L / H=10$ and 50$)$. In the case of slender beams with $(L / H=200)$, a great increasing of $\eta_{n l} / \eta_{l}$ is observed at small amplitudes $(a / H) \in[0 ; 2]$. For the values of $a / H=2$ and greater, the ratio $\eta_{n l} / \eta_{l}$ remains approximately constant. Fig. 5 shows the affect on the loss factor ratio of the first three vibration modes. As can be observed, the ratio $\eta_{n l} / \eta_{l}$ due to the second and third $(n=2$ and 3 ) modes of vibrations, initially decreases with $a / H$ and increases for the first mode of vibration $(n=1)$.

Nonlinear forced vibration analysis is carried out in this study to analyse the hardening changes of laminated composite beams. As seen from Figs. 6 and 7, the geometric parameters $H_{f} / H_{c}$ and $L / H$ have strong effects on the nonlinear behaviour. In theses figures, some more pronounced hardening effects are obtained with thin cores $\left(H_{f} / H_{c}=7\right)$ and for slender beams $(L / H=200)$. Fig. 8 shows

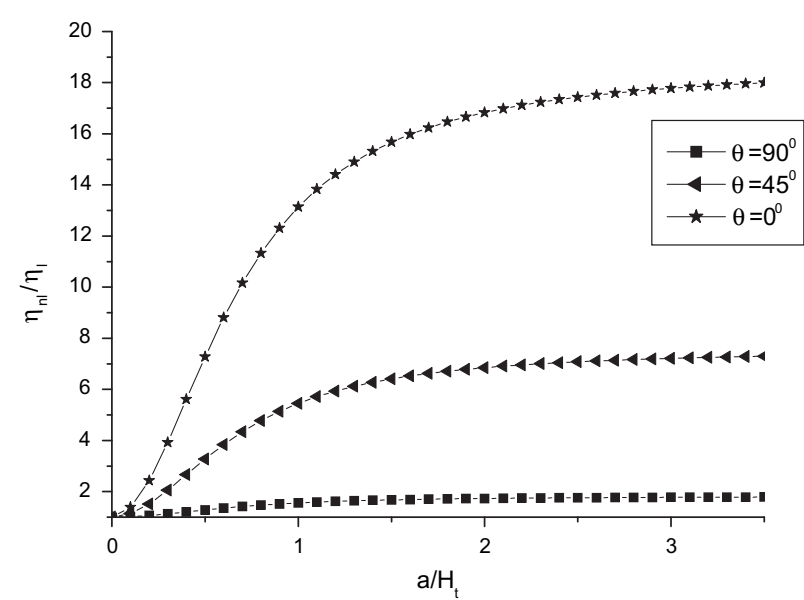

Fig. 3. Loss factor ratio $\eta_{n l} / \eta_{l}$ as a function of the vibration amplitude $\left(a / H_{t}\right)$ for various values of $\theta$ with Touratier model; $b=1 ; H_{f} / H_{c}=7 ; L / H_{t}=100$

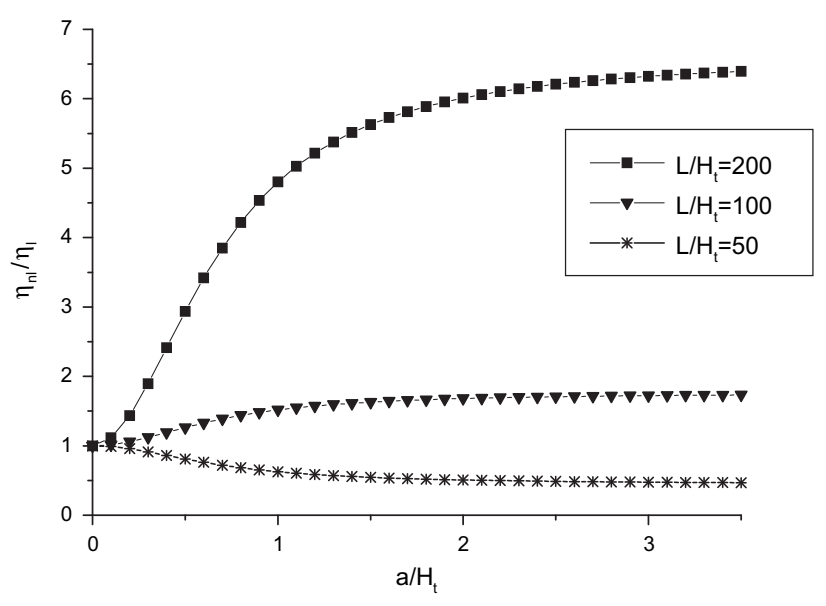

Fig. 4. Loss factor $\eta_{n l} / \eta_{l}$ as a function of the vibration amplitude $\left(a / H_{t}\right)$ for various values of $L / H_{t}$ with Touratier model; $b=1 ; H_{f} / H_{c}=7 ; L / H_{t}=100$ and $\theta=90^{\circ}$.

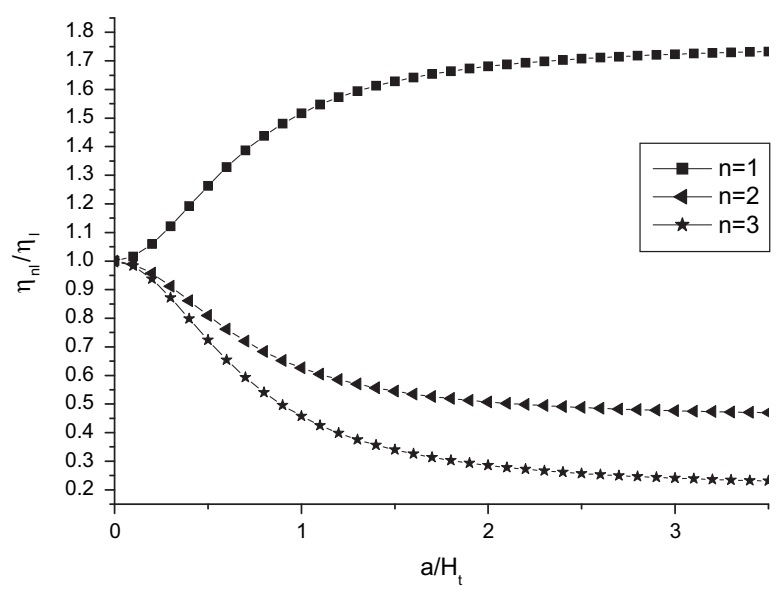

Fig. 5. Loss factor $\eta_{n l} / \eta_{l}$ as a function of the vibration amplitude $\left(a / H_{t}\right)$ for various modes of vibrations $(n=1-3)$ with Touratier model; $b=1 ; H_{f} / H_{c}=7 ; L / H_{t}=100$ and $\theta=90$ and; $L / H_{t}=100$. 


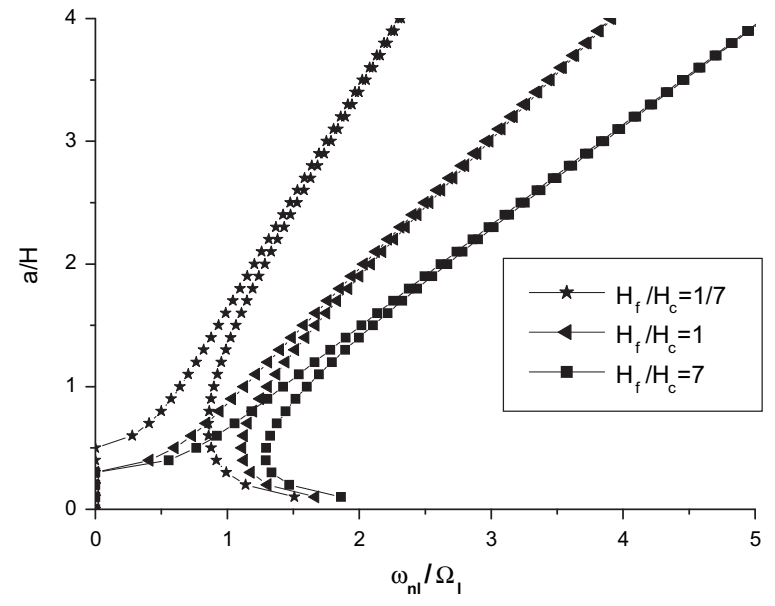

Fig. 6. Forced linear frequency amplitude response for various values of $H_{f} / H_{c}$ with Touratier model; $\theta=90^{\circ} ; L / H_{t}=50 ; H_{t}=0.01 . b=4 H_{t}$ and $Q=1000$.

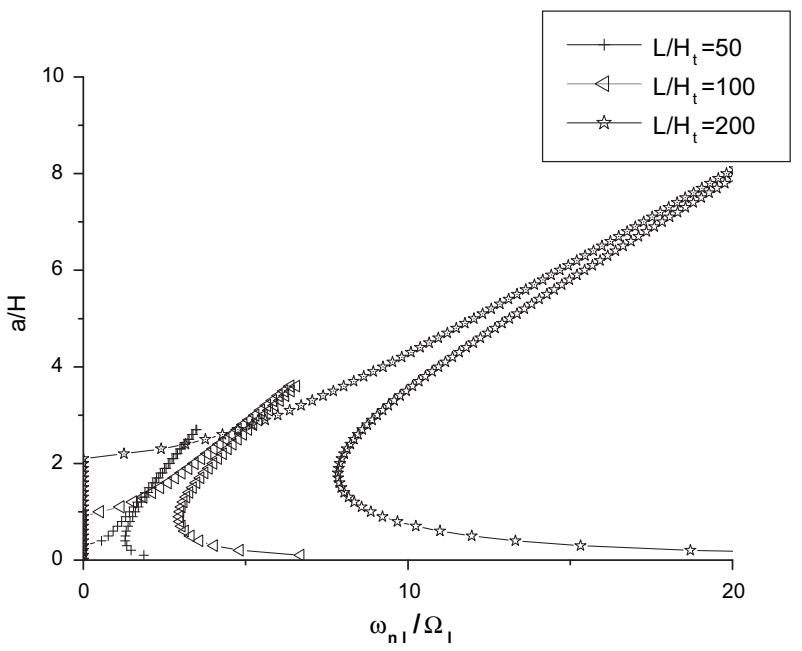

Fig. 7. Forced linear frequency amplitude response for various values of $\mathrm{L} / \mathrm{H}_{\mathrm{t}}$ with Touratier model; $\theta=90^{\circ} ; H_{f} / H_{c}=7 ; H_{t}=0.01 . b=4 H_{t}$ and $Q=1000$.

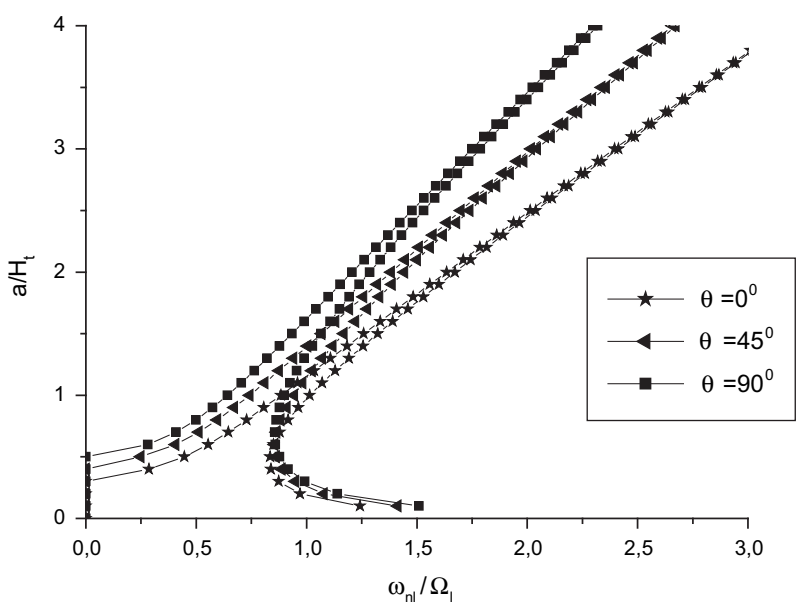

Fig. 8. Forced linear frequency amplitude response for various values of $\theta$ with Touratier model; $H_{f} / H_{c}=7 ; L / H_{t}=50 ; H_{\mathrm{t}}=0.01$. $\mathrm{b}=4 \mathrm{H}_{\mathrm{t}}$ and $Q=1000$. that a softer effect can be achieved by using a soft core, in which, the fibre orientation angle $\theta$ is of $90^{\circ}$.

\section{Conclusion}

Nonlinear forced vibration analysis of laminated composite beams was investigated. Higher order zig-zag theories were used for the displacement field. Based on the harmonic balance method and Galerkin procedure, a scalar complex nonlinear amplitude-frequency relationship was established and a closed form analytical solution for this problem was determined.

Parametric studies indicated that the geometrical parameters $H_{f} / H_{c}$ and $L / H$ have strong effects on the loss factor ratio $\eta_{n l} / \eta_{l}$ and the hardening changes for forced vibration analysis. The material properties of the reinforced fibre composite core have also a great influence on the loss ratio $\eta_{n l} / \eta_{l}$ and the hardening changes. Therefore, the soft core with a fibre angle orientation of $90^{\circ}$ is more suitable for passive vibration control of laminated composite beams, especially in the case of large amplitude excitations. This research provides a good foundation fore future investigations and contributes to the understanding of nonlinear damping properties of other type of structures under dynamic loads.

\section{References}

[1] Gibson RF, Plunkett R. Dynamic stiffness and damping of reinforced composite material. Shock Vib Dig 1977;9:9-17.

[2] Gibson RF, Wilson DG. Dynamic mechanical properties of fiber-reinforced composite materials. Shock Vib Dig 1979;11:3-11.

[3] Nakra BC. Vibration control with viscoelastic material, II. Shock Vib Dig 1981;13:17-20.

[4] Nakra BC. Vibration control with viscoelastic material, II. Shock Vib Dig 1984;16:17-22.

[5] Heng H, Belouatar S, Poitier-Ferry M, Daya EM. Review and assessment of various theories for modelling sandwich composites. Compos Struct 2008;84:282-92.

[6] Rao MK. Frequency and loss factors of sandwich beams under various bandary conditions. J Mech Eng Sci 1978;20(5):271-82.

[7] Rikards R. Finite element analysis of vibration and damping of laminated composites. Compos Struct 1993;24:193-204.

[8] Bhimaraddi A. Sandwich beam theory and the analysis of constrained layer damping. J Sound Vib 1995;179:591-602.

[9] Kovac EJ, Anderson WJ, Scott RA. Forced non-linear vibration of damped sandwich beam. J Sound Vib 1971;17:25-39.

[10] Hyer MW, Anderson WJ, Scott RA. Nonlinear vibrations of three-layer beam with viscoelastic core I: Theory. J Sound Vib 1976;46:121-36.

[11] Hyer MW, Anderson WJ, Scott RA. Nonlinear vibrations of three-layer beam with viscoelastic core II: Experiment. J. Sound Vib. 1978;61:25-30.

[12] Emam SA, Nayfeh AH. Postbuckling and free vibrations of composite beams. Compos Struct 2009;88:636-42.

[13] Belouettar S, Azrar L, Daya EM, Laptev V, Potier Ferry M. Active control of nonlinear vibration of sandwich piezoelectric beams: a simplified approach. Comput Struct 2008;86:386-97.

[14] Reissner E. The effect of transverse shear deformation on the bending of elastic plates. ASME, J Appl Mech 1945;12:69-76.

[15] Mindlin RD. Influence of rotatory inertia and shear in flexural motions of isotropic elastic plates. J Appl Mech 1951;18:1031-6.

[16] Pagano NJ. Exact solutions for composite laminates in cylindrical bending. J Comput Mater 1969;3:398-411.

[17] Timoshenko SP. On the transverse vibration of bars with uniform crosssection. Philos Mag 1922;43:125-31.

[18] Khatua TP, Cheung YK. Bending and vibration of multilayer sandwich beams and plates. Int J Num Methods Eng 1973;6:11-24.

[19] Chandrashekhara K, Krisnamurthy K, Roy S. Free vibration of composite beams including rotary inertia and shear deformation. Compos Struct 1990;14:269-79.

[20] Liew KM, Huang YQ. Bending and buckling of thick symmetric rectangular laminates using the moving least square differential quadrature method. Int J Mech Sci 2003;45:95-114.

[21] Huang YQ Li QS. Bending and buckling analysis of antisymmetric laminates using the moving least square differential quadrature method. Comput Methods Appl Mech Eng 2004:193:3471-92.

[22] Reddy JN. A simple higher-order theory of laminated composite plate. J Appl Mech 1984;51:745-52.

[23] Touratier M. An efficient standard plate theory. Int J Eng Sci 1991;529:901-16

[24] Afaq KS, Karama M, Mistou S. Un nouveau modèle raffiné pour les structures multicouches. In Comptes rendues des 13éme journées nationales sur les composites. Strasbourg; 2003. p. 289-92. 
[25] Rao MK, Desai YM. Analytical solution for vibrations of laminated and sandwich plates using mixed theory. Compos Struct 2004;63:361-73.

[26] RaO MK, Scherbatiuk K, Deesai YM, Shah AH. Natural vibrations of laminated and sandwich plates. J Eng Mech 2004;130:1268-78.

[27] Kapuria S, Dumir PC, Jain NK. Assessment of zig-zag theory for static loading buckling, free and forced response of composite and sandwich beam. Compos Struct 2004;64:317-27.

[28] Zinoviev PA, Ermakov YN. Energy dissipation in composite materials. Lancaster (PA): Technomic Publishing Co., Inc.; 1994.

[29] Marcelo TP, Victor HC. Linear viscoelastic analysis of straight and curved thinwalled laminated composite beams. Int J Solids Struct 2008;45:3466-93.

[30] Anastasia HM, Rami HA. A multi-scale framework for layered composites with thermo-rheologically complex behaviours. Int J Solids Struct 2008;45: 2937-63.
31] Melo JDD, Radford DW. Viscoelastic characterization of transversely isotropic composite laminate. J Compos Mater 2003;37:129-45.

[32] Daya EM, Azrar L, Poitier Ferry M. An amplitude equation for the non-linear vibration of viscoelastically damped sandwich beams. J Sound Vib 2004;271:789-813.

[33] Bilasse M, Daya EM, Azrar L. Linear and nonlinear vibrations analysis of viscoelastic sandwich beams. J Sound Vib 2010;329:4950-69.

[34] Reddy JN. A simplified higher-order theory for laminated composite plates. J Appl Mech 1984;51:745-52.

[35] Shi G, Voyiadjis GZ. A sixth-order theory of shear deformable beams with variational consistent boundary conditions. J Appl Mech 2011;78:1-11. 021019.

[36] Challamel N. Higher-order shear beam theories and enriched continuum. Mech Res Commun 2011;38:388-92.

[37] MATLAB 7.1. Natick (MA): The MathWorks Inc.; 2006. 